\section{Psicologia Escolar \\ e Educacional}

RELATO DE PRÁTICAS PROFISSIONAIS

DOI: http://dx.doi.org/ 10.1590/2175-35392021233959

Localizador - e233959

\title{
CIBERCULTURA EM QUESTÃO: REFLEXÕES ACERCA DA FORMAÇÃO EM PSICOLOGIA
}

\author{
Ingrid Faria Gianordoli-Nascimento ${ }^{1} \mathbb{D}$; Flaviane da Costa Oliveira ${ }^{2} \mathbb{D}$; Luiz Paulo Rocha Vinhal ${ }^{1} \mathbb{D}$; Gislaine \\ Leoncio Motti ${ }^{1} \mathbb{D}$
}

\begin{abstract}
RESUMO
A cibercultura se anuncia em novas dinâmicas de interação e comunicação, mediadas por recursos tecnológicos, que afetam inúmeros campos da vida em sociedade - seja nos âmbitos econômico, político ou pessoal. Tal cenário fomenta inúmeras questões acerca da subjetividade e das relações sociais contemporâneas frente as interações virtuais. A disciplina "Processos Psicossociais na Cibercultura", ofertada à graduação em Psicologia, buscou promover um olhar crítico sobre características da relação entre tecnologia, sujeito e sociedade. Refletimos sobre a importância atribuída, pelos alunos, à temática da cibercultura frente à formação acadêmica e profissional, ponderando sobre novas temáticas e demandas para os currículos em Psicologia. A disciplina possibilitou a construção, ainda que temporária, de um espaço de reflexão conjunta para discentes e docentes - cenário que permitiu alterações na visão dos alunos sobre a cibercultura, reforçando a necessidade de uma formação em Psicologia atenta aos novos processos e demandas presentes na sociedade.
\end{abstract}

Palavras-chave: ensino da psicologia; currículo; tecnologia

\section{Cyberculture under discussion: reflections on Psychology formation}

\begin{abstract}
Cyberculture is announced in new dynamics of interaction and communication, mediated by technological resources, which affect innumerable fields of life in society - whether in the economic, political or personal spheres. This scenario promotes countless questions about subjectivity and contemporary social relations in the face of virtual interactions. The discipline "Psychosocial Processes in Cyberculture", offered in Psychology graduation, sought to promote a critical look at characteristics of the relation between technology, subject and society. We reflected on the importance attributed, by the students, to the theme of cyberculture in academic and professional formation, considering new themes and demands for the curricula in Psychology. The discipline enabled the construction, albeit temporary, of a reflection space for students and teachers - a scenario that enabled changes in students' views on cyberculture, reinforcing the need for formation in Psychology alert to the new processes and demands present in society.
\end{abstract}

Keywords: teaching of psychology; curriculum; technology

\section{Cibercultura en cuestión: reflexiones acerca de la formación en Psicología}

\section{RESUMEN}

La cibercultura se anuncia en nuevas dinámicas de interacción y comunicación, mediadas por recursos tecnológicos, que afectan innúmeros campos de la vida en sociedad - sea en los ámbitos económico, político o personal. Tal escenario fomenta innúmeras cuestiones acerca de la subjetividad y de las relaciones sociales contemporáneas frente a las interacciones virtuales. La asignatura "Procesos Psicosociales en la Cibercultura", ofrecida a la graduación en Psicología, buscó promover una mirada crítica sobre características de la relación entre tecnología, sujeto y sociedad. Pensamos -sobre la importancia atribuida, por los alumnos, la temática de la cibercultura frente a la formación académica y profesional, ponderando sobre nuevas temáticas y demandas para los currículos en Psicología. La asignatura posibilitó la construcción, aunque temporaria, de un espacio de reflexión conjunta para discentes y docentes - escenario que posibilitó alteraciones en la visión de los alumnos sobre la cibercultura, reforzando la necesidad de una formación en Psicología atenta a los nuevos procesos y demandas presentes en la sociedad.

Palabras clave: enseñanza de la psicología; currículo; tecnología

\footnotetext{
${ }^{1}$ Universidade Federal de Minas Gerais - Belo Horizonte-MG -Brasil; ingridfgian@gmail.com; Ipvinhal@hotmail.com; gisamotti@ gmail.com

${ }^{2}$ Universidade Federal do Espírito Santo - Vitória - ES - Brasil; flavianecoliveira@gmail.com
} 


\section{INTRODUÇÃO}

Inúmeros campos da vida em sociedade - seja no âmbito econômico, político ou pessoal - são afetados pelo fenômeno da cibercultura, que é hoje indissociável da experiência cotidiana. Lemos (2015) destaca que a cibercultura pode ser compreendida como o tempo em que vivemos, isto é, como um conjunto de práticas e de recursos próprios de um período histórico, caracterizado pelo capitalismo pós-industrial e pela pós-modernidade.

Ao longo do século XX, as interfaces tecnológicas se converteram em mediadores da interação social: do surgimento dos computadores em ambiente militar, na década de 1940, até os avanços de hardware e software que culminaram na popularização da internet, na década de 1990. Neste sentido, não se trata apenas de recursos tecnológicos, mas sim de veículos de interação com potenciais usos nas esferas públicas e privadas. A internet, os computadores e os smartphones, por exemplo, são recursos essenciais para a comunicação cotidiana, potencializam organizações de eventos e mobilizações políticas, mas também podem fornecer informações para bases de sistemas de vigilância ou controle de dados.

Em 2013, uma onda de mobilização que já havia se espalhado por países europeus, árabes e Estados Unidos - denunciando regimes e reivindicando direitos - chega ao Brasil. Os protestos, que se iniciaram em torno da pauta de redução da tarifa do transporte público, se ampliaram ao agregar inúmeras reivindicações nas áreas de saúde, de educação e contra a realização da Copa do Mundo de 2014. Silva e Ziviani (2014) organizaram um conjunto de textos sobre o cenário das manifestações no Brasil em junho de 2013, chamadas Jornadas de Junho, com ênfase na apresentação da mobilização entre ruas e redes, que povoou o cenário urbano de forma inovadora.

A cibercultura afeta as dimensões de tempo e espaço, fomentando inúmeras questões acerca da subjetividade e das relações sociais contemporâneas. Ao flexibilizar a experiência de interação entre seus usuários, rompem-se as fronteiras territoriais (Lemos, 2007) e altera-se a relação temporal (presente, passado e futuro) com a informação. A digitalização de nossos registros e comunicações permite uma presença que sofre constantes atualizações (Lévy, 1999).

Cientes da importância destas características sociais de nosso tempo, nossa equipe de trabalho - composta por estudantes de graduação e pós-graduação em Psicologia da Universidade Federal de Minas Gerais (UFMG) - se aventurou em estudos e pesquisas acerca da cibercultura enquanto fonte, instrumento e objeto de pesquisa em Psicologia Social (Oliveira, Rocha, Gianordoli-Nascimento, Naiff, \& Ávila, 2017). As pesquisas em nível de mestrado tomavam materiais de caráter documental disponíveis na internet, como fontes de pesquisa: acervo on-line de revista (Oliveira, 2013; Moreira, 2017), blogs (Breugelmans, 2016; Póvoa, 2017; Faleiro, 2018), redes sociais e jogos virtuais (Vinhal, 2019). Em nível de doutorado, investigou-se a construção de memória e representações sociais na plataforma YouTube Brasil (Oliveira, 2019). Cabe situar que, gradativamente, tais pesquisas avançaram na compreensão da cibercultura enquanto um objeto de pesquisa, averiguando os impactos deste fenômeno sobre a subjetividade contemporânea. Deste modo, passou-se de uma apreensão deste ambiente como apenas fonte de pesquisa para um tratamento que o considera como espaço de produção de conhecimentos populares e relações intergrupais, propondo uma visão integrada das esferas on-line e off-line.

Ao identificar uma lacuna referente às interfaces possíveis da cibercultura frente à subjetividade, nossa equipe voltou-se para a questão da formação em Psicologia. Tais problematizações apareciam, até então, de modo disperso em inquietações dos alunos ao longo de outras disciplinas da formação, por exemplo, com a questão dos atendimentos psicológicos on-line.

Ao realizarmos um levantamento acerca das grades curriculares dos cursos mais bem avaliados pelo Exame Nacional do Desempenho dos Estudantes (ENADE) de 2018, foram identificados 34 cursos de Psicologia oferecidos em universidades públicas com avaliação 5 (maior nota do ranqueamento). Cabe dizer que o ENADE consiste em uma avaliação nacional promovida pelo Ministério da Educação (MEC), voltada para a mensuração do desempenho de alunos de graduação em todo o país. Destes, foram sorteadas nove universidades para a análise curricular, sendo a UFMG acrescentada ao levantamento, visto que os pesquisadores encontravam-se vinculados a esta instituição.

Ao buscar e analisar as 10 grades curriculares selecionadas, percebemos que nenhuma fazia menção direta, a partir dos títulos das disciplinas, a questões relativas ao fenômeno da cibercultura. É possível inferir, disto, que não se trata de tópico considerado central na proposta de formação destes profissionais - o que não significa afirmar que a temática não tenha sido tangenciada durante o desenvolvimento de disciplinas outras.

Neste contexto, formulamos uma proposta de disciplina nomeada "Processos Psicossociais na Cibercultura", ofertada no primeiro semestre de 2018 para a graduação em Psicologia da UFMG. A ementa situava conceitos-chave de autores clássicos e contemporâneos, apresentando as principais contribuições das Ciências Sociais, da Comunicação, da Filosofia e da Psicologia na compreensão deste fenômeno. Assim, buscamos promover um olhar crítico dos estudantes sobre as características da relação entre tecnologia, sujeito e sociedade, evitando a patologização indiscriminada dos fenômenos. 
Este trabalho objetiva ponderar sobre a experiência docente nesta disciplina exploratória, localizando seus efeitos sobre a visão dos estudantes acerca da cibercultura. Refletimos ainda sobre a importância atribuída, pelos próprios alunos, à cibercultura frente a sua formação nos âmbitos acadêmico e profissional, localizando novas temáticas e demandas para os currículos em Psicologia.

\section{DESCREVENDO A EXPERIÊNCIA}

A disciplina Processos Psicossociais na Cibercultura foi ofertada como créditos optativos no âmbito do Departamento de Psicologia da UFMG, para alunos de quaisquer períodos da graduação sem pré-requisitos. $A$ primeira aula aconteceu no dia 22 de março de 2018, com uma turma composta por 19 matriculados, sendo 13 alunos concluintes.

Para iniciarmos a disciplina, traçamos a linha de partida dos alunos em relação ao tema, solicitando aos presentes na primeira aula (18 alunos) que descrevessem cinco termos ou expressões que viessem à mente ao citarmos a palavra "cibercultura". A representação do conjunto de associações (palavras ou expressões citadas pelos estudantes) foi sintetizada na forma de nuvem de palavras, como demonstrado na Figura 1. Na representação, quanto maior o termo, maior a sua frequência. Foram desconsideradas as palavras e expressões que apareciam apenas uma vez.

É importante ressaltar que esta tarefa serviu a dois propósitos para a equipe docente: o primeiro, identificar qual o conhecimento prévio dos alunos a respeito da cibercultura; o segundo, traçar uma linha de base para identificar possíveis mudanças naquilo que os alunos compreendem por cibercultura. Ao final da disciplina solicitamos aos estudantes que realizassem outra tarefa de associação a partir do mesmo termo, acompanhado por um questionário sobre a experiência da disciplina. $A$ Figura 2 apresenta o conjunto de associações dos alunos ao final da disciplina.

Podemos perceber que a expressão mais frequente na Figura 1 é "redes sociais" ( $f=8$ ), ao passo que existem outras palavras com frequência considerável, como: "tecnologia" ( $f=5)$; "virtual" e "internet" ( $f=4)$; "vício", "relações interpessoais" e "mudanças nas relações sociais" ( $f=3)$. Ainda vemos expressões como "atualidade", "alienação", "interação", "digital", "distância vs proximidade" e "anonimato" com frequência dois ( $f=2)$. As demais palavras e expressões presentes, foram desconsideradas por apresentar frequência igual a $1(f=1)$.

$\mathrm{Na}$ Figura 1 podemos perceber um forte uso de termos populares relacionados a cibercultura (redes sociais, tecnologia e internet), mas também aspectos negativos e patológicos, expressos pelas palavras "vício" e "alienação". Conforme Nicolaci-da-Costa (2002) tais elementos estão muito presentes na forma como a mídia aborda a presença da tecnologia e os possíveis

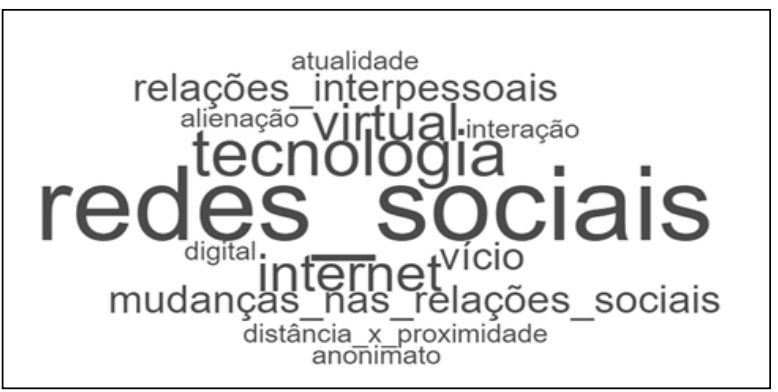

Figura 1. Nuvem de palavras - Evocações dos alunos durante a primeira aula da disciplina Fonte: Autoria própria (2019).

malefícios advindos desse contato, dessa forma, fomentam argumentos do senso comum que geram um conflito interno nos usuários que se deparam com uma experiência pessoal positiva do uso da internet.

Na Figura 2, podemos visualizar a maior predominância do termo "virtual" ( $f=8)$, embora também seja relevante o termo "tecnologia" $(f=6)$. Com frequência considerável, surgem também os termos "território" e "internet" ( $f=4)$; "desterritorialização", "interação" e "real" ( $f=3)$. Aparecem também na nuvem de palavras, com frequência 2, expressões como "interatividade", "redes_sociais", "ciberespaço", "informação", "digital” e "mudança".

A análise dos elementos que compõem a Figura 2 demonstra que algumas palavras se mantêm tendo seu significado ampliado como ocorre com o termo virtual e redes sociais. Já outros termos mencionados, tais como: território, desterritorialização e interatividade; retomam conceitos trabalhados ao longo da disciplina sinalizando uma apropriação do discurso científico acerca do fenômeno.

O cronograma elaborado pela equipe docente abordou, no primeiro momento, conceitos cruciais

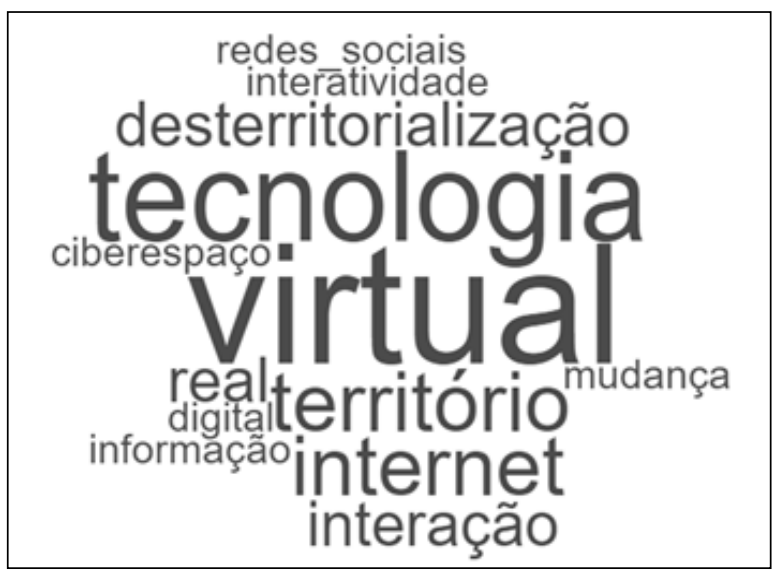

Figura 2. Nuvem de palavras - Evocações dos alunos durante a última aula da disciplina Fonte: Autoria própria (2019). 
para discussão de quaisquer temáticas relacionadas à cibercultura. Neste sentido, exploramos conceitos e problematizações de teóricos da cibercultura (Rüdiger, 2013), tais como: real/virtual/atual (Lévy, 1996, 1999); o conceito de cibercultura (Lévy, 1999; Lemos, 2015; Santaella, 2005; a cibercultura e a Psicologia Social (Mazzotti \& Campos, 2014; Nicolaci-da-Costa, 2002); processos de desterritorialização, reterritorialização e desreterritorialização (Lemos, 2007); interatividade (Mielniczuk, 2001); sociabilidade (Ribeiro, 2001); e memória no ciberespaço (Dodebei \& Gouveia, 2008; Bell \& Gemmel, 2010).

Os primeiros encontros tomaram um teor mais expositivo devido às dificuldades percebidas na compreensão da discussão envolvendo real/virtual/atual, tendo em vista que se tratou do primeiro aspecto conceitual apresentado na disciplina e crucial para seu andamento. De forma ampla, discutimos como os artefatos tecnológicos presentes em nosso cotidiano influenciavam as relações interpessoais; questionamos as tendências de se polarizar a tecnologia como algo exclusivamente bom ou mal e, finalmente, abrimos a conversa para alternativas a respeito da prática psicológica mediada pela tecnologia (impacto da educação a distância, atendimentos psicológicos on-line, cyberbullying, redes sociais, relacionamentos a distância). Tal metodologia de ensino, que proporcionou discussões mais críticas e densas, inspirou-se em propostas como a de Soares \& Veríssimo (2010) que destacam a importância da intersubjetividade na relação professor-aluno para a formação dos alunos de Psicologia.

\section{Reflexões discentes sobre a experiência da disciplina}

A aplicação de questionário e elaboração de memorial ao final da disciplina possibilitou uma via de observação da trajetória dos discente ao longo do semestre. Os resultados do questionário indicaram que, em relação à formação acadêmica, 92,9\% dos alunos consideraram a discussão relevante ou totalmente relevante. $A$ totalidade dos estudantes reconheceu possíveis efeitos para a atuação profissional futura. Dentre as temáticas trabalhadas, as de maior interesse foram: conceito de real/virtual; sociabilidade no ciberespaço; psicologia e cibercultura; dimensões de tempo e espaço; e interatividade. Os alunos relataram ainda, que gostariam de aprofundar-se nas seguintes temáticas: cyberbullying e relações interpessoais e afetivas.

A partir da experiência proporcionada pela disciplina, os estudantes identificaram três possíveis influências na atuação profissional futura. A primeira, se relaciona às discussões teóricas realizadas em sala de aula, sistematizando conceitos e potencialidades de aspectos da cibercultura, oferecendo um olhar crítico à visão do senso comum que tende a patologizar a tecnologia. $\mathrm{O}$ segundo ponto diz respeito à ampliação da compreensão a respeito dos impactos do digital no cotidiano, oferecendo ferramentas para uma expansão de práticas do psicólogo em diferentes campos de atuação. Finalmente, o terceiro ponto indica a impossibilidade de dissociar o ambiente virtual da experiência cotidiana, uma vez que a contemporaneidade é marcada por novos espaços de interação social que não devem ser negligenciados na prática do psicólogo.

A proposta avaliativa de encerramento da disciplina tratou-se da elaboração de memorial, ou seja, a construção de um texto reflexivo acerca da trajetória na disciplina e da apreensão dos conceitos trabalhados no campo da Psicologia. A análise dos memoriais destacou a importância dos instrumentos e aparelhos tecnológicos que viabilizam maior armazenamento e digitalização de dados. Foram ressaltados também os aspectos psicossociais das relações que se dão nesse território. 0 ambiente da sala de aula foi apresentado como espaço privilegiado, que estabeleceu uma dinâmica importante para construção dos saberes e desenvolvimento das discussões, gerando um embate entre conhecimentos do senso comum e científicos.

\section{Reflexões docentes sobre inclusão da cibercultura na formação em Psicologia}

A experiência de ministrar a disciplina foi ao mesmo tempo um desafio e uma aventura. Como docentes, tratamos de discussões que já nos eram habituais no âmbito da pesquisa, mas que no espaço da sala de aula mobilizaram discussões calorosas - em especial sobre temas que atravessam o cotidiano, tais como as redes sociais, os atendimentos on-line ou o vício na internet.

Considerando a formação em Psicologia, Magalhães (2011) convida a refletir sobre sua ampliação a partir do paradigma da complexidade, visando "um ensino de Psicologia que ajude a construir um processo de formação integral dos sujeitos" (p. 269). Tratar de novas bases teóricas e ideológicas no processo educativo é um desafio em inúmeras áreas de conhecimento, uma vez que os saberes consolidados parecem não dar conta das transformações impostas pela realidade. De modo semelhante, partimos da cibercultura como campo teórico de diálogo para a formação em Psicologia, uma vez que os processos psicossociais mediados pela tecnologia apontam brechas para a formação profissional, e, uma vez identificados esses limites, há necessidade de se pensar alternativas.

Além de refletir sobre a necessidade de expansão conceitual da área, parece relevante situar a necessidade de uma perspectiva crítica à neutralidade, tendo em vista a implicação inevitável e necessária dos sujeitos nos processos de produção de conhecimento. Tal perspectiva defendida por Fernandes, Zanella e Bueno (2014) faz da pesquisa em sala de aula um catalisa- 
dor para reposicionar professores e alunos diante do complexo processo de ensinar e aprender, a partir da presença da dialogia e da invenção.

Neste sentido, Amendola (2014) denuncia a existência de uma "tecnificação" do ensino superior como consequência da estratégia universitária de adequar e regular o currículo acadêmico aos critérios das relações de mercado. A autora defende que o exercício da reflexão crítica e da liberdade é condição para o próprio exercício da ética, visto que o "tornar-se psicólogo é mais que uma ação interessada no conhecimento ou uma preocupação com a formação técnico-científica" (p. 979). Para que a prática profissional não se torne alienada e/ou alienante, é preciso que o psicólogo seja capaz de se posicionar perante às demandas contemporâneas da sociedade.

Notamos que a proposta da disciplina foi bem recebida, modificando alguns aspectos da visão dos alunos sobre a cibercultura e apontando o interesse na continuidade da discussão. A experiência da disciplina revelou a urgência dos alunos em contemplar em sua formação o estudo dos impactos das tecnologias digitais na subjetividade. Cabe situar que ao longo da disciplina, tais impactos foram tratados priorizando aspectos coletivos.

Esta experiência possibilitou a construção, ainda que temporária, de um espaço de reflexão conjunta para discentes e docentes. É reforçada a necessidade de uma formação em Psicologia atenta aos novos processos e demandas presentes na sociedade.

\section{REFERÊNCIAS}

Amendola, M. F. (2014). Formação em Psicologia, Demandas Sociais Contemporâneas e Ética: uma Perspectiva. Psicologia: ciência e profissão, 34(4), 971-983. https://doi. org/10.1590/1982-370001762013

Bell, C. G.; Gemmel, G. (2010). O futuro da memória: como essa transformação mudará tudo o que conhecemos (R. B. Vieira, Trad.). Rio de Janeiro: Elsevier.

Bernardes, J. S. (2012). A formação em Psicologia após 50 anos do Primeiro Currículo Nacional da Psicologia alguns desafios atuais. Psicologia: ciência e profissão, 32(num. esp.), 216-231. https://doi.org/10.1590/S141498932012000500016

Resolução CNE/CES № 8 (7 de maio de 2004). Diretrizes Curriculares para os cursos de Psicologia. Diário Oficial da União, Seção I. Brasília, DF: Conselho Nacional de Educação. Retrieved from http://portal.mec.gov.br/cne/arquivos/ pdf/rces08_04.pdf

Breugelmans, J. C. F. (2016). Guardiões da memória, herdeiros da luta: identidade e memória nas publicações dos websites do grupo Hijos por la Identidad y la Justicia contra el Olvido y el Silencio (Dissertação de Mestrado em Psicologia). Universidade Federal de Minas Gerais, Belo Horizonte.

Dodebei, V.; Gouveia, I. (2008). Memória do futuro no ciberespaço: entre lembrar e esquecer. Revista de Ciência da Informação, 9(5), 1-13. Retrieved from http://www.dgz. org.br/out08/Art_02.htm.

Faleiro, L. T. R. (2018). Transtornos alimentares em adolescentes e jovens adultos: uma compreensão à luz das representações sociais (Dissertação de Mestrado). Universidade Federal de Minas Gerais, Belo Horizonte.

Fernandes, A. M. D.; Zanella, A. V.; Bueno, G. (2014). Formação em Psicologia Social: relato de uma experiência de ensino/ pesquisa/intervenção. Fractal, Rev. Psicol., 26(2), 445460. Retrieved from https://www.scielo.br/j/fractal/a/ ww7DwhQHrt7mrHc6pm6JFDC/.

Lemos, A. (2015). Cibercultura (8. ed). Editora Sulina: Porto Alegre.

Lévy, P. (1996). O que é o virtual. (Paulo Neves Trad.). São Paulo: Editora 34.

Lévy, P. (1999). Cibercultura. (Carlos Irineu da Costa Trad.). São Paulo: Editora 34.

Magalhães, S. M. O. (2013). Ensino de Psicologia: limites do atual paradigma e a complementaridade do paradigma da complexidade. Educar em Revista, 48, 265-287. Retrieved from https://www.scielo.br/j/er/a/ NVJsszs8qJZGzcGpr9rjNxC/.

Mazzotti, A. J. A., \& Campos, P. H. F. (2011). Cibercultura: uma nova "era das representações sociais"? In Almeida, A. M. O.; Santos, M. F. S.; Trindade, Z. A. Teoria das Representações Sociais: 50 anos (pp. 457-488). Brasília: TechnoPolitik Editora.

Mielniczuh, L. (2001). Considerações sobre interatividade no contexto das novas mídias. In Palácios, M.; Lemos, A. (Eds.), As Janelas do Ciberespaço (pp. 172-185). Porto Alegre: Sulina.

Moreira, A. H. (2017). Ser mulher e usar drogas: possibilidade de ruptura da norma de gênero (Dissertação de Mestrado em Psicologia). Universidade Federal de Minas Gerais, Belo Horizonte.

Nicolaci-da-Costa, A. M. (2002). Internet: a negatividade do discurso da mídia versus a positividade da experiência pessoal. À qual dar crédito?. Estudos de Psicologia, 7(1), 25-36.

Oliveira, F. C. (2013). "Pau neles, não nos nossos": as Representações Sociais de tráfico de drogas na revista Veja (1968-2010) e suas articulações com a dinâmica identitária (Dissertação de Mestrado em Psicologia). Universidade Federal de Minas Gerais, Belo Horizonte.

Oliveira, F. C. (2019). Batalhas virtuais pela memória: uma análise psicossocial da memória histórica do regime militar no Brasil. (Tese de Doutorado em Psicologia). Universidade Federal de Minas Gerais, Belo Horizonte.

Oliveira, F. C.; Rocha, J. P. D. C.; Gianordoli-Nascimento, I. F.; Naiff, L. A. M.; Ávila, R. F. (2017). Novas páginas de pesquisa em Psicologia Social: o fazer pesquisa na/da internet. Psicologia e Saber Social, 6(2), 186-204. https:// doi.org/10.12957/psi.saber.soc.2017.33558

Póvoa, J. M. (2017). Os sentidos da dor do parto no contexto 
de humanização no Brasil (Dissertação de Mestrado em Psicologia). Universidade Federal de Minas Gerais, Belo Horizonte.

Ribeiro, J. C. S. (2001). Um breve olhar sobre a sociabilidade no ciberespaço. Palácios, M.; Lemos, A. (Eds.), As Janelas do Ciberespaço (pp. 138-150). Porto Alegre: Sulina.

Rüdiger, F. (2013). As teorias da cibercultura: perspectivas, questões e autores. Porto Alegre: Sulina.

Santaella, L. (2005). Três tipos de usuários: o novato, o leigo e o experto. In: L. Santaella (Ed.). Por que as comunicações $e$ as artes estão convergindo? Questões fundamentais da comunicação. (pp. 55-72). São Paulo: Paulus.

Silva, R. H. A. D.; Ziviani, P. (2014). Ruas e redes: dinâmicas dos protestos $B R$. Belo Horizonte: Autêntica.

Soares, L. L. M.; Veríssimo, L. J. (2010). A formação do aluno na graduação em Psicologia pela Pedagogia de Paulo Freire. Psicologia: ciência e profissão, 30(3), 588-603. https://doi. org/10.1590/S1414-98932010000300011

Vinhal, L. P. R. (2019). Disputas de gênero no ambiente virtual do jogo League of Legends (Dissertação de Mestrado em Psicologia). Universidade Federal de Minas Gerais, Belo Horizonte.

Reconhecemos o apoio financeiro da Coordenação de Aperfeiçoamento de Pessoal de Nível Superior (CAPES), com a concessão de bolsas de Mestrado (03/2018 - 07/2019) e de Doutorado (03/2015 - 03/2019); e da Fundação de Amparo à Pesquisa do Estado de Minas Gerais (FAPEMIG) desde 2016, Edital № 02/2016 - Programa Pesquisador Mineiro (Processo PPM-00636-16) e concessão de bolsa de Iniciação Científica (07/2018 - 01/2019).

Recebido: 05 de março de 2010

Aprovado: 26 de dezembro de 2020 